\title{
La influencia del cante jondo de Federico García Lorca en la obra de André Velter
}

\author{
Sidonia BAUER
}

(Universität zu Köln)

EL CANTE JONDO ENTRE LOCALIZACIÓN REGIONAL Y DESLOCALIZACIÓN

Este artículo trata del cante jondo, de su topografía y topología y de cómo, desde Andalucía, penetró en Francia como chant profond a través del proceso concreto de la recepción por parte del poeta contemporáneo André Velter. En este sentido, hay que señalar que el cante jondo de Federico García Lorca, inicialmente, se restringía a la región de Andalucía por su origen y por su definición "El cante jondo (Canto primitivo andaluz)" (García Lorca 1972b: 7-34): "Se trata de un canto puramente andaluz, que ya existía en germen en esta región antes que los gitanos llegaran a ella" (García Lorca 1972b: 10). En esta frase de Lorca encontramos una localización y, al mismo tiempo, un primer movimiento de deslocalización en el motivo recurrente de Lorca: lo gitano. Notablemente, Lorca localiza el cante en la tierra de Andalucía y atribuye, al mismo tiempo, su forma actual a los gitanos, privados de origen determinado: "Y estas gentes, llegando a nuestra Andalucía, unieron los viejísimos elementos nativos con el viejísimo que ellos traían y dieron las definitivas formas a lo que hoy llamamos cante jondo" (García Lorca 1972b: 13). Aunque estos gitanos son españoles, su origen permanece desconocido, secreto y localizado en un Oriente vago que Lorca llama, "[s]egún la versión”, "India” (García Lorca 1972b: 12): "Viene de razas lejanas, atravesando el cementerio de los años y las frondas de los vientos marchitos" (García Lorca 1972b: 18). Sin duda, la figura de lo gitano que reaparece en el Romancero gitano es para Lorca la encarnación a la vez de lo regional y de lo universal: "El libro en conjunto, aunque se llama gitano, es el poema de Andalucía y lo llamo gitano porque el gitano es lo más elevado, lo más profundo, más aristocrático de mi país, lo más representativo de su modo y el que guarda el ascua, la sangre y el alfabeto de la verdad andaluza y universal” (García Lorca 1972c: 50). 
Así, Lorca adopta el estilo del cante jondo también para su Romancero gitano y su Llanto por Ignacio Sánchez Mejías - sus tres obras líricas principales - . Estas pertenecen a la literatura universal y corresponden, sin embargo, al concepto de las literaturas del mundo (Müller 2014: 7). Son escritos, como mediadores de la cultura específicamente andaluza y de tradiciones gitanas, desde una periferia que cancela la dicotomía entre esta y el centro. En este sentido, el poeta gitano José Heredia Maya integra la poesía de Lorca en la cultura literaria de su pueblo marginalizado (cf. “Adiós: En homenaje a Federico" [Heredia Maya 1986: 159]). Lorca se inscribe tanto en lo local como en lo global: su escritura se caracteriza por los dos procesos, de localización del cante jondo y de su deslocalización, abriéndolo al mundo. Su receptor francés Velter se apropia, parcialmente, del conocimiento poético, a la vez arcaico y moderno, de Lorca. Lo relocaliza, en primer lugar, topográficamente en España, en Andalucía (Velter 2008: 71) y, en segundo lugar, lo deslocaliza topológicamente al reclamar el cante jondo como esencial de su propia poética, "nómada” (“j’écris ce que je suis, / dans ce français nomade”, [Velter 2011: 49]) y, por lo tanto, no precisamente fijada a un territorio regional.

El objetivo del presente trabajo es presentar, en un primer momento, la recepción de Lorca en Francia en general y, más específicamente, el interés de Velter por la obra lírica y ensayista de este. Primeramente, estudiaremos las referencias intertextuales de Lorca en Velter que producen una localización del cante jondo y después profundizamos en la deslocalización que hace Velter de la poética del cante jondo como chant profond en aras de su mundialización.

\section{Recepción de Lorca en Francia, especialmente por Velter}

La obra de Federico García Lorca y, especialmente, el Romancero gitano (1924-1927, publicado por la primera vez en 1928), que se menciona con frecuencia ligado al Poema del cante jondo, compuesto poco antes (1921, publicado por primera vez en 1931), es inseparable del discurso que pronunciara el poeta sobre el cante jondo, "El cante jondo. Canto primitivo andaluz", en ocasión del Concurso del Cante Jondo de Granada los días 13 y 14 de junio de 1922 y que fue organizado por Lorca junto a su maestro Manuel de Falla (cf. Rogmann 1981: 14). Toda su obra poética, desde las primeras traducciones al francés, disfrutó de una recepción fuerte en Francia, que continúa hasta el presente. André Velter, poeta contemporáneo nacido en 1945 y jefe de la sección de poesía de Gallimard (cf. Bauer 2015: 103), la editorial más prestigiosa de Francia, presenta un ejemplo notable de la actualidad de la obra lírica de Lorca en el campo de la poesía francesa contemporánea. 
Según el Catálogo General de la BNF (Bibliothèque Nationale de France), las primeras traducciones del Romancero gitano (García Lorca 1937) al francés, como Cinq romances gitanes (García Lorca 1939), y del Poema del cante jondo, como Poème du cante jondo (1939b), datan del año 1939. Sin embargo, las publicaciones aparecen recién en 1954-1955 en la editorial Gallimard, incluidas en las obras completas de Lorca (García Lorca 1954-1955, vol. 2). Pero, para no anticipar demasiado, la primera traducción del Romancero gitano de 1939, realizada por Guy Lévis Mano, vio la luz como publicación en 1946 - Romancero gitan (García Lorca 1946) - porque el traductor fundó su propia editorial (a saber, GLM). No obstante, le siguen pronto otras traducciones, a cargo de F. Gattegno (1942 y 1945 en Alger: E. Charlot) y de Paul Verdevoye (1944 en París: la Nouvelle Édition), que se establecerán tras su inclusión en las obras completas en la editorial Gallimard, en 1954-1955. Asimismo, el Chant funèbre pour Ignacio Sánchez Mejias (Llanto por Ignacio Sánchez Mejías, 1935) por André Belamich, Pierre Darmangeat, Jean Prévost y Jules Supervieille, cuyas traducciones se asegura la editorial Gallimard. Los traductores Pierre Darmangeat y André Belamich se mantienen para la edición del Cante jondo en 1961; una edición anotada del Romancero gitan, seguido del Chant funèbre pour Ignacio Sánchez Mejías por André Belamich, es editada en 2010 por Gallimard. Digna de mención es también la traducción reciente del Romancero gitan y del Chant profond de la mano del poeta contemporáneo Claude Esteban en 1995 (París: Aubier). En una entrevista con motivo del cincuenta aniversario de la editorial Gallimard, André Velter explica la historia de la casa y especialmente el gran éxito del rubro Poésie/Gallimard (cf. Garnier-Duguy 2016). En 1966, Claude Gallimard decidió iniciar el rubro Poésie. Hasta el momento, solo unos pocos poetas habían sido publicados (Apollinaire, Éluard, Prévert, entre otros). Pero en esta nueva edición aparecerá, cronológicamente después de Éluard, García Lorca - el poeta español-, antes de los clásicos Mallarmé, Apollinaire, Claudel, Aragón, Valéry, Queneau, Supervielle, Breton y otros poetas franceses. Solo en 1971-1972 se publican, como poetas españoles, en Poésie/Gallimard también Neruda y Machado. Esta decisión de Claude Gallimard de dar a Lorca un papel de primer orden en la historia de la poesía moderna y contemporánea se explica sin duda en parte también por razones económicas (hoy en día las ventas de las obras de Apollinaire son las más exitosas), desde donde se puede inferir la gran popularidad de estas obras de Lorca entre los receptores franceses.

Sin embargo, en este contexto nos interesa menos la dimensión cuantitativa de la recepción que su modalidad, en particular la adquisición y la transmutación de la poesía de Lorca a través del trabajo que hace Velter. En este sentido, después de haber constatado el efecto sobre la-obra-lavida (cf. Borer 1991) de Velter, hay que señalar las influencias a propósito 
de los temas, de la práctica poética, de la estilística, de la poética y de la poetología. El punto de partida para el presente análisis lo constituye la hipótesis de que el Romancero gitano y su cante jondo irradian en la poesía fiera (lyrisme fauve, Bauer 2015: 328) de Velter, que el poeta formuló por primera vez de manera explícita en 2008 en la obra Tant de soleils dans le sang (Velter 2008 y 2014).

Esta influencia se observa textualmente y debería, así, ser suficiente para confirmar la hipótesis. Sin embargo, agregamos como paratexto una opinión personal de Velter en cuanto al papel que juega Lorca con respecto a su poesía. Su respuesta al interrogarlo acerca de "La influencia del cante jondo de Federico García Lorca en la obra de André Velter" es la siguiente (Correspondencia personal, 25 de abril de 2016):

[T]out García Lorca m'intéresse, mais tu as raison, dans Tant de soleils, c'est Poèmes $d u$ Cante Jondo et Romancero gitan qui résonnent au plus près dans ma quête du "chant profond", et ma quasi obsession du "duende". L'essentiel tient à ce legs de poésie populaire qui ressurgit, irrigue, dynamise soudain l'expression d'une poésie intensément vécue au présent. Garcia Lorca réalise la conjonction incroyablement mystérieuse de deux poésies que rien ne devrait relier: celle, primitive, instinctive, tellurique, du peuple gitan et celle, sophistiquée, érudite, hermétique, d'un Góngora. Il y a chez García Lorca une "lumière obscure" qui me fascine tant elle éclaire les ténèbres et aveugle de midi à cinq heures du soir. Chez lui le sang est sombre et clair, éclatant, violent et suave tout à la fois. On dirait qu'il enchâsse la lune au mitan du soleil pour s'en faire un emblème, et qu'il garde par devers lui une part de la nuit, même en plein jour. Viva Federico!

Estas palabras entusiastas de Velter muestran un fuerte vínculo con Lorca, que en parte es debido a la mencionada búsqueda del cante profundo interno y al ideal poético del duende. Antes de profundizar en las bases poetológicas de la creación lírica tenemos que revelar las referencias interautoriales e intertextuales entre Velter y Lorca.

\section{EJEMPLOS DE REFERENCIAS EXPLÍ́CITAS DE LORCA EN VELTER}

En la entrevista "Recurso al poema" (Garnier-Duguy 2016), Velter reconoce haber devorado al instante, junto a aquellas de Cendrars, Perse, Char, la edición de Poésie/Gallimard de García Lorca de entonces (1966), y “extrañamente antes de Apollinaire”. Su conocimiento de la poesía de Lorca, así, es temprano y va por poco de la mano con su primera obra escrita con Serge Sautreau, Aisha, publicada por Gallimard en 1965. En 1966, cuando Claude Gallimard decidió iniciar el rubro Poésie, 
Velter tenía 21 años de edad, pero la influencia explícita de Lorca en este se muestra solo en 1998, más de treinta años después, exactamente al comienzo del periodo de poesía fiera.. En el plano biográfico, este cambio de estilo desde la poesía seca (lyrisme árido, Bauer 2015: 17) hasta la poesía fiera corresponde con su enamoramiento de Chantal Mauduit. Ambos se conocen en 1996 y llaman a su encuentro amour fol, autocreación según el amour fou de André Breton. En 1998, el amor acaba trágicamente, cuando la alpinista Mauduit, de renombre mundial, a los 34 años de edad, muere en una avalancha en el Himalaya. En su obra más famosa, el tríptico lírico L'amour extrême (las tres alas aparecen por primera vez por separado en 1998, 1999 y 2000, mientras que el tríptico completo aparece en 2007, cf. Velter 2007), se descubre la primera referencia clara a Lorca, a saber, temáticamente a su Llanto por Ignacio Sánchez Mejías, en particular a su último cuarteto de la cuarta canción "Alma ausente":

Tardará mucho tiempo en nacer, si es que nace, un andaluz tan claro, tan rico de aventura.

Yo canto su elegancia con palabras que gimen y recuerdo una brisa triste por los olivos.

(García Lorca 1989: 122)

Aquí Lorca lamenta la pérdida del gran poeta y torero. Velter, por su parte, vive la experiencia dolorosa de la pérdida de su mujer amada. En una dedicatoria a esta, sustituye las características de Ignacio por las de Chantal:

C'est évidemment à García Lorca que je pense, à son Chant funèbre pour Ignacio Sánchez Mejías. J'en transmue de brèves séquences, et te rejoins en ce parler d'Andalousie que tu possédais beaucoup mieux que moi...

Tardará mucho tiempo en nacer, si no es milagro, una mujer tan clara, tan rica de aventuras.

(Velter 2007: 100)

Velter mantiene la cita en español y añade a su poema un asterisco y una traducción francesa. Sigue una descripción abatida del modelo, que también está de luto: "L'avenir, Federico le neutralise simplement en plus tard [...]” (Velter 2007: 101). A partir de este punto, comienzan las palabras de Velter. Para su lamento se ha inspirado, además, en otros versos del Llanto. Así, su "Je dirai” (Velter 2007: 61 y ss.) recuerda al penúltimo cuarteto de "Alma ausente", de Lorca: 
No te conoce nadie. No. Pero yo te canto.

Yo canto para luego tu perfil y tu gracia.

La madurez insigne de tu conocimiento.

$\mathrm{Tu}$ apetencia de muerte y el gusto de tu boca.

La tristeza que tuvo tu valiente alegría.

(García Lorca 1989: 122)

Sin duda, Velter no solo asume el "yo canto para luego" como motivo, sino también el medio retórico de la lista acumulativa por construcciones polisindéticas (Velter 2007: 61, verso 3). La referencia fue inspirada por la característica de la gracia ("gracia”, "grâce”), tanto sugerida en "Je dirai" como directamente pronunciada ("grâce incarnée”, Velter 2007: 61), así como también por la calidad de la alegría ("alegría”, "rire”) que caracteriza, a la vez, al fallecido en Lorca y a la fallecida en Velter:

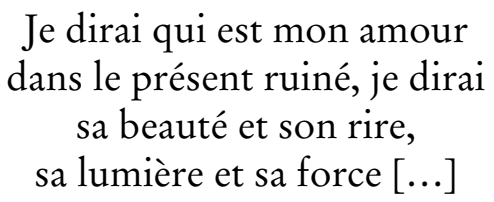

De este modo, en su dolor infinito, Velter se orienta por la estructura fija del poema de Lorca, así como también por su estilo dramático-trágico. Se demostrará que Velter sigue acudiendo a Lorca como fuente de inspiración, de muchas maneras diferentes, hasta el año 2014. La mayoría de sus obras de la lírica fiera refiere a Lorca. A continuación hacemos un listado de algunas de ellas:

Velter, André (2014): Le Tao du Toreo. Arles: Actes Sud. Dibujos de Ernest Pignon-Ernest. Trad. al español por Vivian Lofiego.

Velter, André/Bianu, Zéno (2013): Prendre feu. Paris: Gallimard.

Velter, André (2012): Avec un peu plus de ciel. Paris: Gallimard.

Velter, André (2011): Paseo grande. Paris: Gallimard.

Velter, André (2008): Tant de soleils dans sang [con DVD]. Annecy: Alphabet de l'espace. Dibujos de Ernest Pignon-Ernest, guitarra de Pedro Soler.

Los temas principales en Tant de soleils dans le sang remiten a la muerte y el erotismo, y promulgan el concepto de la poésie vécue (poesía vivida). En Paseo grande, el motivo de los toros, que se encuentra ya en Tant de soleils dans le sang, se convierte en centro de atención, pero ahora aparece más desarrollado. Tant de soleils dans le sang abre y cierra con la tauromaquia; el manifiesto poético Prendre feu, escrito con Zéno Bianu, 
aborda el concepto del duende. El duende se desarrolla de manera performativa en la segunda parte, lírica, del manifiesto, allí nombrado "Le Duende d'Orphée". Le Tao du Toreo consolida la poesía de la tauromachie (cf. Bauer 2016: 195) y por la traducción simultánea de los versos franceses en español obtiene la mayor proximidad posible a la tauromaquia española - de hecho, la tauromaquia francesa está prácticamente ausente en la poesía de Velter-. Aunque Velter, en lo que se refiere a este tema, está naturalmente también en intercambio con Leiris, el lazo con Lorca se hace evidente en medio del verso conductor "Cinq heures du soir" (Velter 2008: 85 y ss.), que no solo cierra Tant de soleils dans le sang como modificación moderada - "Orphée avant cinq heures du soir [cursiva mía]”-, sino que también abre Prendre feu, afilando los sentidos (Velter/Bianu 2013: 11): “Cinq heures du soir. C'est le temps décisif [...]. Instant fatal qui, par la grâce d'un seul poème de Federico García Lorca, n'a pas sombré dans l'oubli, tout en léguant cette trace de sable et de sang où se lève la plus vive de nos vies", y lo finaliza incluso en español (Velter/ Bianu 2013: 59): “A las cinco de la tarde est décidément un temps béni pour les pyromanes de l'esprit". El último poema, escrito con gracia estilística, se llama también "Cinq heures du soir, infiniment [cursiva mía]" (Velter/Bianu 2013: 99-104). Este motivo recurrente, "A las cinco de la tarde”, es una cita de Llanto por Ignacio Sánchez Mejías, precisamente de la primera canción, “La cogida y la muerte” (García Lorca 1989: 111-113).

El verso iterativo que fluye por esta apertura del lamento es justamente el "A las cinco de la tarde". Se trata del momento del inicio de la muerte, del impulso de la muerte, de la línea divisoria - o mejor, del punto - de separación temporal que divide la vida de la muerte antes de que se termine la lucha y siga esta y, con ella, la memoria del o de los muertos con respeto y con amor. Prendre feu es el elogio de la vida frente a la muerte, es la conciencia de la vida en su máxima intensidad y, al mismo tiempo, su representación artística. Para Velter, el encuentro con esta intensidad de la vida frente a la muerte llega a encarnarse en el rostro de Chantal y, para Lorca, en el rostro del torero. Esta ecuación de Chantal como amante, y del torero como criatura amada disuelve el lirismo oscuro de Velter y aporta luz y claridad en su poesía fiera. "Fauve" se debe entender en este sentido como "animal" porque es cuestión principalmente de toros y de toreros. Por un lado, detrás del rostro del torero y de los toros (como su sinécdoque) se esconde la faz de la amante, invocada en Le Tao du Toreo, Prendre feu, Avec un peu plus de ciel, Paseo grande y Tant de soleils dans le sang; el duelo específico de la muerte de los toros, las heridas de los toreros y la figura de Orfeo forman en conjunto un llanto "infinito" en torno a la amante, cuyo "perfil” y cuya "gracia” jamás se repiten, sino que siempre se trasforman en nuevas formas. Por otro lado, enfrentarse al juego con la muerte, característico de la tauromaquia e inherente tam- 
bién a las obras Cante jondo y Romancero gitano, de Lorca, significa una confrontación con la propia muerte. La postura frente a la muerte se hace fructífera poéticamente. Los toreros generan una gran elegancia para luchar contra aquella y esta es expresión de lo mejor de ellos (en concreto, de José Tomás, cf. Velter 2014: 7).

Después de haber mostrado algunas de las correspondencias líricas más evidentes, se discutirá la práctica de la oralidad (oralité) y, posteriormente, el concepto del cante jondo.

\section{PRÁCtICA Y POÉTICA: EL CANTE JONDO COMO POESÍA VIVIDA}

En su conferencia "El Cante jondo. Canto primitivo andaluz" (1972b: 7-34), Lorca define el cante jondo como específico de los gitanos, siendo la "siguiriya” gitana su expresión más pura: "La 'siguiriya' gitana es la canción tipo del grupo 'cante jondo”" (1972a: 38), "es el único canto que en nuestro continente se ha conservado en toda su pureza, tanto por su composición como por su estilo, las cualidades que lleva en sí el canto primitivo de los pueblos orientales" (1972a: 38-39). "[C]onsulta al aire, a la tierra, al mar, a la luna, a cosas tan sencillas como el romero, la violeta y el pájaro" (1972b: 24), "llega [...] a producirnos la impresión de una prosa cantada” (1972b: 10), “[es el] alma de nuestra alma” (1972b: 13), “[v] iene del primer llanto y el primer beso" (1972b: 18). Las expresiones del más alto dolor ("dolor" y "pena”, 1972b: 24, 28 y 33) están contenidas en ello, en sus bases se encuentran "El Amor y la Muerte...” (1972b: 19). El "medio tono" (1972b: 21) existe raramente, se tira al cante jondo a los extremos "del dolor y de la Amor" (1972b: 28). Sus elementos son la noche y la oscuridad. Los elementos naturales como el suelo, el agua, el aire y la luna pertenecen a su universo.

Ya temprano, Velter se distinguió como un cultivador del chant profond. Así lo explicó en sus autorretratos: "Il y a un chant profond, mémoire secrète des hommes et des dieux, un chant au-delà des temps, de l'Histoire, des frontières et des rites. Celui-là ne rend compte à personne, il s'allie aux éléments et porte les destinées. Il naît et renaît sans cesse, comme la mort et l'amour" (Velter 1991: 15). Una diferencia es que, con Ouvrir le chant (Velter 1994), él no está buscando la aparición del cantar en los gitanos de Andalucía, sino que la encuentra, según esta obra, en los pueblos nómadas y sedentarios de Afganistán, Tíbet y la India (en las sierras del Ladakh, Himalaya). Atribuye la canción original, que comienza con palabras, gritos, profanaciones, exorcismos y otras declamaciones orales, a un área sagrada que es universal. Esta concepción del chant profond no está en contradicción con la del cante jondo de Lorca, a mi parecer, por el hecho de que esta canción es cantada por los calé y encuentra 
sus orígenes lejanos en "el camino" y, entre otras cosas, viene del Oriente (García Lorca 1972b: 12). El origen, que excede límites y apunta de nuevo a un humano general, es, por lo tanto, esencial. Este es el que Velter intenta descubrir tanto en otras culturas como en sí mismo. El inicio del cantar con frecuencia parece mitológico o cosmogónico, como primer tono (primer llanto, primer verso o primera imagen) (García Lorca 1972b: 11) en el universo, o como la primera figura que aparece y no tiene nombre. Así, encontramos en Tant de soleils dans le sang (Velter 2008: 15 y ss.) a Eros o la fuerza erótica, pero aún no tiene nombre y surge “à l'instinct” (Velter 2008: 16), instintivamente. Generalmente, Velter se autodesigna "poète d'instinct” (Velter 1991: 57). El lado oscuro de su poesía, vuelto hacia Eros y Tánatos en sus extremos, es su poesía fiera, y está muy cerca de la de Lorca. No es en vano que Velter acuda regularmente a Lorca como compañero de camino en este periodo.

A la serie "Toros", en Tant de soleils dans le sang le sigue la suite programática "Ceux de la poésie vécue” (Velter 2008: 49-70). Tras esta, se encuentra también un poema homenaje a Lorca: “A toi Federico" (Velter 2008: 67-69). En este revelador poema, construido, como el cante jondo, solo por versos con rimas asonantes (y cortas, irregulares) y con estrofas irregulares de dos a seis versos, Velter destaca lo que admira en la-obra-lavida de Lorca: el "arrière-pays de sang” que nos "jette en roulotte sur les routes” (estr. 1) - es decir, Velter respeta su atracción por los gitanos (estr. 4 ) - . Además, estima su coraje de vivir, donde amenaza la muerte por el cuchillo, y de cantar sobre este peligro (estr. 2).

El sentimiento trágico de la vida que Velter comparte con Lorca lo ve encarnado por los gitanos: “D’ailleurs dans les yeux des Gitans, / tu lisais que vivre est une tragédie / pleine de grâce, de tourments" (estr. 4). También atribuye a los gitanos la elegancia, a pesar del sufrimiento (estr. $3,4)$. A continuación, elogia la fuerza del deseo y de la pasión de Federico, que compara con el sol y el fuego (estr. 5). Por otra parte, Velter está de acuerdo con el cantar de Lorca sobre el peligro, el riesgo, la belleza, la vulnerabilidad, la energía, el orgullo, la ausencia de la docilidad y su humanidad (Velter 2008: 68 y ss.). Evoca las “chansons populaires / mêlées aux saveurs symphoniques de la terre!” (estr. 15) y, conclusivamente, exalta el duende que se muestra en Lorca - y, con Lorca, en Velter - de instinto y de intuición por la transmutación de la intensidad vivida en poesía maravillosa: “Avec toi, Federico, le duende / devient d'instinct miracle d'encre noire" (estr. 17).

Al encomio sigue la serie de poemas “Andalousies” (Velter 2008: 7186), y, al final, a mitad de la referencia a Ignacio Sánchez Mejías, el poema introductorio "Orphée par nuit noire" (Velter 2008: 15 y ss.) se ve retomado por el verso "Orphée avant cinq heures du soir" (Velter 2008: 85 y ss.). El ciclo de poemas llega, así, a su fin. Las “Andalousies” adoptan 
temas y, parcialmente, también formas del Poema del cante jondo y del Romancero gitano. Los poemas, escritos a la vez en estilo árido y fiero, evocan la división en luz y sombra del paisaje andaluz, como el color que se conoce de Lorca. La luz y la oscuridad, un claroscuro, forman el tenso contraste entre el sol y la noche (véase, en El cante jondo, el poema “Arqueros” y, en el Romancero gitano, el poema "Muerte de Antoñito el Camborio"). El Guadalquivir, además de las ciudades de Granada y Sevilla, se cantan (véase, en El cante jondo, el poema "Sevilla"), una taberna es evocada (véase, en El cante jondo, el poema "Café cantante"), la muerte es conjurada en los colores negro y rojo, una Virgen y dos santos se cantan (para Velter, un motivo excepcional y eco posible de "San Miguel”, "San Rafael”, "San Gabriel” u otros santos del Cante jondo). Una balada cuyo escenario se desarrolla bajo la luna, cuyos actores son un caballero y una niña, adicionalmente recuerda imágenes del Romancero gitano, precisamente del "Romance de la luna, luna" (Cante jondo). El encantamiento de la "Chanson pour renaître à Grenade" (Velter 2008: 81 y ss.) aspira a romper el estrecho cuadro del origen, así como el de los ritmos y de los bailes (otra referencia al Cante jondo es el poema "Danza"). Además de un deseo excesivo, el estribillo "Que se déchire la trame des origines, / des rythmes et des danses!” (Velter 2008: 81 y ss.) significa una abertura, en la cual se mezclan los orígenes - de modo ejemplar en Granada y Sevilla $-\mathrm{y}$, en consecuencia, pierden su importancia para el presente. En lugar del cuadro, se encuentra una vastedad que corresponde al chant profond y que se puede identificar como la meta a conseguir en la vida: el chant profond excede fronteras, tiempos (incluyendo el pasado y el futuro) y nacionalidades; su símbolo son los gitanos. En el último poema, "La guitarra” (Velter 2008: 83 y ss.), que cierra la serie - el instrumento es aquí de nuevo una alusión a los poemas de Lorca que evocan tonos y llantos de guitarra-, Velter junta los conceptos del cante jondo y del chant profond ("au Chant profond des nuits, / au Cante Jondo d'Andalousie", Velter 2008: 84), así como del cante jondo/chant profond y del duende. Porque lo que señala en Prendre feu metafóricamente como duende, "ce chant des origines qui résonne déjà au fin fond de l'avenir” (Velter/Bianu 2013: 21), en realidad es la definición del cante jondo; esto es extendido por ambos poetas al arte en general: “L'art n'est rien s'il n'est pas cet appel du large. L'art n'est rien s'il cède un seul arpent de son cœur” (Velter/Bianu 2013: 21).

También el párrafo siguiente, construido de manera más compleja, tiene por base la identificación de Lorca con los gitanos como figuras artísticas, que son "apátridas universales" ("En artiste d'ici et maintenant et de nulle part cependant, en apatride universel”, Velter/Bianu 2013: 21). Se consagran al misterio del mundo como alquimistas y artesanos sin plomo y sin oro (Velter/Bianu 2013: 22), pero se dedican a la trascendencia 
y la practican como un arte marcial (un ejemplo es la corrida). El duende se asocia con Orfeo, al arte del "duende d'Orphée” (Velter/Bianu 2013: 63): “Nous allons aimer ce qui revient à l'amour” (Velter/Bianu 2013: 45). El instinto de la vida, de acuerdo con esta concepción del arte (poético), se descubre en su confrontación con la muerte en toda su intensidad y corresponde a la voluntad de amor. Así, incluso de la oscuridad (de la muerte) misma, de manera alquimístico-musical, surge un sol gracias a la canción, semejante al llanto del poeta-cantante acompañado de su instrumento de cuerdas.

A través de este homenaje a Lorca, Velter también valoriza su propia poética y su práctica poética. Aunque cita “La guitarra” de Lorca, el poema es más específicamente un homenaje al guitarrista flamenco español Pedro Soler, que acompaña a Velter en sus recitales y lo inspira. El libro de poemas Tant de soleils dans le sang es acompañado de un DVD que muestra uno de los recitales con Pedro Soler; al mismo tiempo, el subtítulo $U n$ livre-récital avec Pedro Soler sirve como introducción del nuevo género lírico que une escritura y oralidad. También en la práctica poética se reconoce, por tanto, una verdadera relación con el cante jondo de Lorca. Esta implicación social mediante la poesía en el pueblo, en la cité, presenta otra característica común de ambos poetas - debe mencionarse que Velter fue cofundador del festival nacional de poetas Le Printemps des Poètes, que en 2015, bajo la dirección de Jean-Pierre Siméon, recibió el Premio Goncourt de poesía - . La implicación de Lorca con el festival del cante jondo y, más tarde, con el teatro itinerante La Barraca es conocida (cf. Rogmann 1981: 6).

El nacimiento del canto lírico, unido a la voz, desde el deseo del poeta (sus sueños o realidades), la intervención de la poesía en la injusticia que existe en la sociedad (como la defensa de los gitanos, de los negros y de los homosexuales por parte de Lorca) ("Nous allons défendre ce qui se veut sans défense", Velter/Bianu 2013: 44), el enlace a la vida plena, intensa, incluso a costa de sus riesgos inherentes, son aspectos centrales de lo que Velter, en la línea de Alain Jouffroy, entiende por poésie vécue (cf. Jouffroy 1994).

Para terminar, se debe mencionar que el cante jondo, en su traducción al francés como chant profond, se libera de su atadura regional y étnica para integrarse en un movimiento más amplio de "apátridas universales". Velter (y también Bianu) se cuentan entre los numerosos poetas de la poesía mundial que traspasan fronteras estrechas. En este sentido, Lorca (y sus ideales poéticos del duende y del cante jondo) se ve incorporado a una sociedad de poetas de la poesía vivida, quienes lo asumen como uno de sus faros. ¿Con razón? Velter, durante veinte años (1987-2007), difundió poesía del mundo a través de la radio (cf. Bauer 2015: 102). Desde la editorial Gallimard transmite "poésies du monde entier" (cf. Le Printemps 
des Poètes 2016). Promueve la recepción de Lorca en Francia y aprovecha la oportunidad para destacar la utilidad y la actualidad de su pensamiento lírico, perspectiva, esta, muy necesaria para una lectura mundial.

\section{BiBLIOGRAFÍA}

BAUer, Sidonia (2016): Einführung in die französische Gegenwartspoesie. Strukturiert anhand des Programms der Mondopoethik. Berlin: Frank \& Timme.

- (2015): La poésie vécue d'André Velter. Berlin: Frank \& Timme.

Beltrán FernÁNDEz de los Ríos, Luis (1986): La arquitectura del bumo: una reconstrucción del Romancero Gitano de Federico García Lorca. London: Tamesis.

Borer, Alain (1991): Arthur Rimbaud: Cuvre-vie. Paris: Arléa.

Castro, Eduardo (ed.) (1986): Versos para Federico. Lorca como tema poético. Madrid: Universidad de Murcia.

EIch, Christoph (1976 [1958]): Federico García Lorca. Poeta de la intensidad. Versión española de Gonzalo Sobejano. Madrid: Biblioteca Románica Hispánica.

García Lorca, Federico (21989 [1981]): “Llanto por Ignacio Sánchez Mejías”. En: Diván del Tamarit [1931-1935]. Llanto por Ignacio Sánchez Mejías [1934]. Sonetos [1924-1936]. Madrid: Alianza Editorial, pp. 101-120.

- (1985 [1921]): Poema del cante jondo. Romancero gitano. Edición de Allen Josephs y Juan Caballero. Madrid: Ediciones Cátedra.

— (21972a [1969]): “Arquitectura del 'cante jondo'”. En: Prosa. Madrid: Alianza Editorial, pp. 35-45.

— (21972b [1969]): "El cante jondo". En: Prosa. Madrid: Alianza Editorial, pp. 7-34.

— (21972c [1969]): "Romancero gitano". En: Prosa. Madrid: Alianza Editorial, pp. 47-90.

— ( ${ }^{2} 1972 d$ [1969]): “Teoría y juego del duende”. En: Prosa. Madrid: Alianza Editorial, pp. 169-189.

- (1954-1955): Euvres complètes. Poésies. Romancero gitan. Le Poète à NewYork. Chant funèbre pour Ignacio Sanchez Mejias. Poèmes galiciens. Divan du Tamarit. Poèmes détachés / trad. de l'espagnol par A. Belamich, P. Darmangeat, Cl. Couffon, B. [Bernard] Sésé, J. Supervielle et J. Prévost. Vol. 2. Paris: Gallimard.

- (1946): Romancero gitan. Paris: GLM.

- (1939a): Cinq romances gitanes. Texte espagnol et traduction par Guy LévisMano. Paris: GLM.

- (1939b): Poème du cante jondo. Traduit par Pierre Darmangeat. Rodez: Éditions du Méridien.

- (1937): Primer romancero gitano. Palabras para Federico por Rafael Alberti. Barcelona: R. Sopena. 
Garnier-Duguy, Gwen (2016): "Recours au poème. La collection Poésie/Gallimard fête ses 50 ans: rencontre avec André Velter". En: <http://www.recoursaupoeme.fr/rencontre/la-collection-poésiegallimard-fête-ses-50-ans-rencontre-avec-andré-velter/gwen-garnier> (última visita: 12/01/2016).

Heredia Maya, José (1986): “Adiós: En homenaje a Federico”. En: Castro, Eduardo (ed.): Versos para Federico: Lorca como tema poético. Murcia: Universidad de Murcia, p. 159.

Jouffroy, Alain (1994): Manifeste de la poésie vécue. Paris: Gallimard.

LEPRINTEMPS DES POÈTES (2016): “André Velter”. En: <http://www.printempsdespoetes.com/index.php?url=poetheque/poetes_fiche.php\&cle=27> (última visita: $11 / 10 / 2016)$.

Lorenz, Günter W. (1963): Federico García Lorca in Selbstzengnissen und Bilddokumenten. Hamburg: Rowohlt.

Miller, Norman C. (1978): García Lorca's Poema del Cante Jondo. London: Tamesis.

Müller, Gesine (2014): “Die Debatte Weltliteratur-Literaturen der Welt”. En: Müller, Gesine (ed.): Verlag Macht Weltliteratur. Lateinamerikanisch-deutsche Kulturtransfers zwischen internationalem Literaturbetrieb und Übersetzungspolitik. Berlin: Verlag Walter Frey, pp. 7-17.

Noiret, Gérard (2004): André Velter: ouvrir le chant. Paris: Jean-Michel Place.

Ortiz de Montellano, Bernardo (1998): “Romancero gitano”. En: Schneider, Mario Luis: García Lorca y México. México: Universidad Nacional Autónoma de México, pp. 131-134.

Rogmann, Horst (1981): García Lorca. Darmstadt: Wissenschaftliche Buchgesellschaft.

SOREL, André (1997): Yo, García Lorca. Tafalla: Txalaparta.

Umbral, Francisco (1968): Lorca, poeta maldito. Barcelona: Editorial Planeta.

Velter, André (2014a): Le Tao du Toreo. Dessins d'Ernest Pignon-Ernest. Trad. espagnole de Vivian Lofiego. Arles: Actes Sud.

- (2014b): Tant de soleils dans sang. Un livre-récital avec Pedro Soler et sept poèmes-tracts avec Ernest Pignon-Ernest. Paris: Gallimard.

- (2012): Avec un peu plus de ciel. Paris: Gallimard.

- (2011): Paseo grande. Un livre-récital avec Olivier Deck et sept poèmes-talismans avec Antonio Segui. Paris: Gallimard.

- (2008): Tant de soleils dans sang. Dessins d'Ernest Pignon-Ernest, guitare de Pedro Soler. Annecy: Alphabet de l'Espace.

- (2007): L'amour extrême. Poèmes pour Chantal Mauduit. Paris: Gallimard.

- (1994): Ouvrir le chant: partitions. Suivi de deux entretiens avec Jean-Marie Sidaner. Pantin/Québec: Le Castor Astral/Écrits des Forges.

- (1991): Autoportraits. Vénissieux: Éditions Paroles d'Aube.

Velter, André/Bianu, Zéno (2013): Prendre feu. Paris: Gallimard. 